\title{
VOICES OF ENTREPRENEURS:
}

\section{A REVIEW OF ENTREPRENEURS' PERCEPTIONS OF SME COVID-19 SUPPORT MEASURES IN SOUTH AFRICA}

\author{
Lisle Svenson ${ }^{1}$ Orcid ID: 0000-0002-0978-6228
}

\begin{abstract}
:
This article sheds the spotlight on support mechanisms for small businesses that are struggling as a result of the Covid-19 pandemic. The data was collated during a two-part webinar series on lockdown stories of small businesses in the Western Cape, the effects thereof, support mechanisms and possible solutions to the challenges faced. The webinars, run in August 2020, were hosted by the Economics and Management Sciences Faculty of the University of the Western Cape. The article compiles the contributions of panel members from a crosssection of stakeholders from business, government and academia. Potential solutions and support mechanisms available from various spheres of society - government, business and academia - are discussed as part of the arsenal available to small businesses in the face of the negative impact of Covid-19 on their businesses.
\end{abstract}

\section{Introduction}

The National Development Plan (NDP) states that by 2030 poverty of income will be eliminated and inequality reduced, employment would increase and per capita income would be raised, amongst other things. More specifically, it is envisaged that employment growth, amongst other things, will occur through growing small- and medium-sized enterprises. However, South African businesses have been hit hard by the coronavirus pandemic, especially those classified as small businesses and amidst these are survivalist businesses. Before the pandemic, the country was already in a downward economic spiral. The lockdown has exacerbated the economic challenges that South Africans are facing (Professor Michelle Esau, 27 August 2020).

The purpose of this article is to help shed light on potential solutions and support mechanisms available to small businesses, following the effects of the Covid-19 pandemic and the lockdown, instituted by the South African government as of 27 March 2020. The data was obtained from the participation of small businesses and representatives from the Small Business Development Agency (SEDA), Local Government, the financial sector, and academics from the University of the Western Cape. The two-part webinar series, hosted by the Economics and Management Sciences Faculty of the University of the Western Cape, was held in August 2020.

The key questions addressed in the webinars and in this article are as follows:

1. What kind of support (beyond financial relief) is being considered to small businesses that may have collapsed under lockdown conditions, especially regarding support to female entrepreneurs and those who are the sole breadwinners of their families?

2. What happens to those who do not qualify for the relief package or who may have slipped through the cracks and who did not apply?

3. What happens to business owners who have lost confidence in their abilities as entrepreneurs?

${ }^{1}$ University of the Western Cape, School of Business and Finance

Email: Isvenson@uwc.ac.za 
4. How are universities such as the UWC, with its focus on being engaged with the community, engaging in the challenges that confront small business owners?

5. What advice can be given to small business owners about the post-COVID entrepreneurial context?

\section{Background}

On 27 August 2020, the EMS Faculty of the University of the Western Cape hosted the second webinar of a twopart series focusing on the lockdown stories of small businesses in the Western Cape, the first of which focussed on the effect and challenges of the pandemic on their businesses, their lives, employees and that of their families. The second webinar focussed on the solutions to the challenges faced, and the various support mechanisms available to small businesses.

The panel members from a cross section of society were invited to elaborate on some of the institutional support mechanisms that are available for small business operators that are facing serious viability challenges, emanating from the negative effects of the Covid-19 pandemic. A second aim of the webinar initiated by UWC was to initiate a solution-building process, and to integrate the solutions and support mechanisms discussed by the participants into a guide and toolkit from which small business owners could draw upon as part of their arsenal in the fight against Covid-19 and into the post-Covid-19 era.

According to Professor Vivienne Lawack who participated in the webinars, UWC adopts an integrative community engagement process. The approach adopted is that of open dialogue and community participation in line with the principle of infusing community engagement with the University's teaching, learning, and research across the various disciplines.

Following the discussion focusing on the challenges faced by small businesses, the owners, employees and their families, the panellists participating in the second webinar, who focussed on solutions and support measures in place or being implemented by government and business, highlighted the following kinds of assistance available, as well as the challenges pertaining to their uptake. The key points relating to these are summarised in the following sections. These are categorised according to the roles of important stakeholders - representatives of which were involved in the webinar series and also play an important part in assisting the development of the small business sector in South Africa.

\section{Role of UWC in providing support to Small Business}

Lawack (2020) stated that in an effort to focus on small business, UWC would soon launch its 'Zone Learning' initiative, also called 'The Zone'. This will consist of two parts. The one leg, housed in the Faculty of Economic and Management Sciences will be the Small Business Clinic. The second leg to be launched is the Entrepreneurial Law Clinic. These vehicles will work together, allowing academics and students in the Faculties of Economic and Management Sciences and Law, to cross-fertilise and enhance their specialist knowledge and competencies as well as benefit local small businesses. The aim is to assist them to develop and grow sustainably. Apart from cross-faculty interaction, it is envisaged that The Zone will also work in collaboration with key role players from government, industry and civil society and leverage the support mechanisms available from these institutions. With its focus on small business, The Zone will therefore be especially well-placed to offer opportunities where students can learn and develop entrepreneurial skill sets, and learn to adopt and craft a pioneering mindset in aid of all role players - the university, supporting institutions local small businesses and the community at large.

\section{Role of ICT in Supporting Small Business}

Drawing on his professional experience at policy level and the research conducted within the Department of Information Systems at UWC's Faculty of Economic and Management Sciences, Pather (2020) provided valuable insight into the digital ecosystem and how this can be harnessed in support of small and microenterprises. In addition to providing practical examples of research conducted in the department, he also expressed the importance of research in providing information on the challenges, efficacy of the support measures, and potential solutions to the particular challenges faced by small businesses in South Africa.

Pather (2020) stated that when looking at the digital ecosystem and the role of ICT in supporting small and microenterprises, the starting point as well as the underlying problem is the historical inequitable distribution of telecom services. This is a fundamental aspect which needs to be addressed, as it forms the backbone of ICT. Unfortunately, this inequality is represented both geographically and in terms of income levels. An intervention therefore needs to be put in place to address this 'digital divide' in order to realize any positive social and economic 
outcomes for small and microenterprises, and to start benefiting the poor and marginalised masses, as well as the broader business sector and society in general. Furthermore, research indicates that ample ICT-related support for small and microenterprises are generally available. The broad array of ICT-related services include support for business growth, from the idea through to launch and mentorship, as well as software to support business operations. In particular, cloud-based services have become very important, to start supporting all types of small businesses. This is due to the multiplicity of ICT functionality that can be made available via cloud-based services. However, the big challenge for SMMEs has been their inability to access and appropriate these, in order for the businesses to benefit from the services and functionality that can be derived from it (Pather, 2020).

One of the support measures highlighted and that is available to SMMEs is provided by the Department of Economic Development and Tourism in the Western Cape, which harnesses and deploys this technology to support small businesses. UWC together with other universities and partners, were involved in the early stages and they formed part of the reference group for the project. Since then a website, as well as an app has been launched to support businesses from start-up to scaling. For example, apart from a variety of other initiatives, a 'Tech volunteer' program was initiated when Covid-19 started. The aim of the program is to provide advisory services to small businesses, with the assistance of student volunteers who sit on the advisory panel. Students from the UWC Department of Information systems were also involved in it. Another example involves a national mentorship movement, where with the help of a technology platform in the form of a mobile app is used to support small businesses (Pather, 2020).

In general, a plethora of software applications are also available to support and enable marketing, customer sales, service, accounting, finance and other applications. These can easily be made accessible to small businesses. Furthermore, several categories of open-source software and platforms are freely available. These include email, Office Suite or e-commerce, should anybody want to start a business and sell things online. Although some of it is available at a cost, there are very low entry requirements. In summary, a variety of open-source software is freely available to the average small and micro-entrepreneur. However, the challenge is that South Africa's digital ecosystem which provides these services is multifaceted, and it may be too fragmented or complex to be accessed by small and microenterprises. Although a lot of support is available, the average small business is generally not able to harness the effective use of ICT for its operational use and to support its growth needs. Insufficient social appropriation of ICTs is therefore a major concern in the South African small business context (Pather, 2020).

At the macro-policy-environmental level, a White Paper on a National Integrated ICT policy, representing the country's digital ecosystem, was gazetted in 2016. Two key aspects or strategies relating to this ecosystem and the effect of ICT on small businesses are noteworthy from an industry growth perspective. The first involves the mechanisms to develop and nurture small businesses in the ICT sector. The second involves developing an enabling environment where ICT is used to support and advance the operations and effectiveness of small businesses. This includes how to catalyse innovative business ideas or 'disruptors' in areas where the core value proposition is dependent on ICTs. As part of the strategy an industry growth value chain for small businesses has also been recognized. The National Department of Telecoms and Digital Strategies is the custodian of the strategy and responsible for fleshing out and putting into place the overarching strategy as well as drive its implementation (Pather, 2020).

\section{Ecosystem challenges}

Pather (2020) stated that in terms of ecosystem challenges, the lack of awareness and marketing of the incentives and support available to small businesses constitute the biggest failures. Consequently, South Africa has a very low level of social innovation by entrepreneurs, as reported by the Network Readiness Index (2019), This is because the appropriation of ICT in the ecosystem requires ready access by entrepreneurs. The basis of this premise is founded on four pillars, namely (1) technology (2) people (3) governance and (4) impact. From an African perspective, South Africa performs well in terms of technology and content. This is due to the involvement of multi-national businesses and a relatively established and favourable environment for these players in the metropolitan areas of the country. However, data from the Network Readiness Report (2019), shows that the biggest challenge South Africa faces relates to impact, measures access and the quality of life of a country's citizens. Data from Stats SA also reflects this concerning position.

\section{Initiatives to increase SMME adoption of ICT}

Pather (2020) stated that as a university, UWC has conducted lots of other research around the ICT and small business nexus. Importantly, this includes research to facilitate the adoption of ICT: For example, how ICT can be 
improved, support available to SMMEs, the causes of low adoption and developing participatory design, and including the use of different kinds of software and infrastructure. One study identified some of the antecedents that cause businesses to be technology averse, i.e. technophobia behind the average small and microenterprise, and how to disconfirm it, for example, through doing participatory research. Another example involved investigating the barriers and how to overcome these. The major findings emanating from this research is that most of the SMMEs involved in the studies, experienced difficulty in integrating technology into their businesses and they lacked understanding of how to appropriate it. The affordability of data is another key issue. However, this is a national matter that requires attention at a higher level. Research from universities regarding pricing is another area where universities can assist by using data available from their research to lobby government and industry organisations to lower the cost of data.

In summary, research conducted reflects a lack of awareness and marketing of ICT services available to SMMEs. This inhibits their growth, development and competitiveness. A programme focused on creating awareness and marketing of these services is therefore recommended. Secondly, Skills Development initiatives involving ICT literacy as well as other business training programmes supported by mentoring and coaching is required. Although ICT literacy was found to build the confidence of SMMEs, it is only the starting point. Assisting nascent entrepreneurs, start-ups and established SMMEs with developing their ideas, for example through mentorship and coaching in a way that's integrated with skills development and underpinned with an understanding of how ICT can be harnessed as an enabler to support these ventures, will play a major role in overcoming some of the myriad challenges faced by SMMEs (Pather, 2020).

\section{Role of the Small Enterprise Development Agency (SEDA)}

SEDA provides non-financial business development support to small businesses. Zaida Jackson, manager of the four SEDA branches in the Western Cape, stated that SEDA has revisited and refocused their interventions in order to help subsidize the interventions their small business clients required during the Covid-19 pandemic and lockdown. It has focused approximately $90 \%$ of the 2020 financial year budget on Covid-19 relief measures. However, roughly $80 \%$ of the budget is focussed on informal sector businesses. Different categories of informal businesses are assisted, including those in clothing and textiles, automotive support services, personal care, hair and beauty, spaza shops, bakeries and fruit and vegetable sellers. Other types of small business entrepreneurs who operate their businesses from home, such as those who make and sell cooked food as well as shisanyama-type businesses, are also supported. These categories of businesses have been prioritised by the Department of Small Business and they form and increasing majority of clients that SEDA is tasked to focus on (Jackson, 2020).

A major part of the service SEDA provides in the small business ecosystem, is prefunding support to informal-type businesses. This prepares and assists them in becoming registered businesses that are able to access funding and other available support schemes. Facilitating the compliance of small and microbusinesses to meet the requirements of the CIPC, SARS and UIF if they employ staff, etc., thus plays a key role for SEDA. Once small and microbusinesses meet the compliance hurdle and the businesses have been granted funding from a funding institution/s, SEDA assists them with post-support. This takes the form of mentoring and coaching from the business advisors who are in SEDA's employ. They also offer specialized training, such as bookkeeping and financial management, to help small businesses develop and adopt more formal-type business processes. Apart from the pre- and post-funding assistance provided by SEDA and funding provided by SEFA', the lack of marketing and awareness around these services is a major challenge that reduces the number of SMEs benefiting from the funding grants and facilities available to small and microenterprises (Jackson, 2020).

\section{Role of Government}

In order to understand the role played by government, in particular the role of local and provincial municipalities in mitigating the impact of Covid-19 on small businesses, it is important to understand that the Covid-19 lockdown was announced and instituted shortly after the municipal budgets for the 2020 financial year (starting in March 2020) had been approved. This meant that Government (at local, provincial and at national levels) entered the lockdown period without being financially or materially prepared to respond to the calls from SMMEs for support. Subsequently, they reallocated resources to ensure that they were able to start dealing with the increased requirements and requests for assistance. Apart from the direct impact of the Covid-19 pandemic and the consequent lockdown,

\footnotetext{
The Small Enterprise Finance Agency (SOC) Limited (sefa) provides financial products and services to qualifying SMMEs and co-operatives, as defined in the National Small Business Act of 1996 and amended in 2004, through a hybrid of wholesale and direct lending channels within various sectors.
} 
it also exposed increased levels of inequality and poverty. This was one of the most important areas of impact on local communities in South Africa. Therefore, more support needs to be focused on the 'disadvantaged areas' where people live and secure their livelihoods. This is particularly true in terms of development efforts, including education, training and skills development, to support small and microenterprises in the townships and to equip the future generation of business owners with skills to earn a living and not be dependent on government handouts (Madikane, 2020).

\section{Regulations and the need for information sharing}

Although the Covid-19 lockdown regulations are mostly controlled by the South African government at a national level, the municipalities at provincial and local levels must operate in accordance with the national regulations. The regulations provided information about (1) who is allowed to work (2) when they are allowed to work and (3) the conditions under which particular groups are allowed to work or continue their operations. During the lockdown period many people, including SMMEs, started looking for this information. The dissemination thereof became necessary, with the need thereof spiking every time the lockdown levels changed or new regulations came into effect. As SMMES required confirmation of the parameters within which they could operate at local as well as provincial levels of government, adequate two-way communication platforms and structures needed to be put into place to limit the uncertainty in the business environment. Communication platforms, including WhatsApp groups, Facebook, emails, and SMS platforms were activated to serve this need. These were important infrastructural components that were needed to drive communication down to where it was needed; enabling local communities to share information between and among themselves. Referring to the Overstrand Municipality, Madikane (2020) stated: "One of the things we picked up in many of these pandemics is that the survival of small businesses depends largely on the community that they serve".

In reaction to the Covid-19 lockdown, the SMME Safety tickets intervention was also rolled out in municipalities in the Western Cape. It focussed on distributing information pamphlets, sanitizers and masks; assisting SMMEs to follow the regulations, implementing the necessary health protocols and contributing towards mitigating the negative effects of the coronavirus. With this intervention, SMMEs in the townships were provided with safety kits, and they were shown how to use these within their businesses. Equipped with this know-how, they were able to operate, and showcase the health protocols within their communities. In the process, it engendered a sense of community through participation. The use of Covid-19 ambassadors supplemented these by educating people on the importance of wearing masks and maintaining a social distance. The ambassadors also interacted with small businesses in the townships. The interaction of these ambassadors enabled municipalities to remain aware of the needs of the locals and of the businesses in the townships. An information pack was also developed to provide direct support to SMMEs, and to a certain extent, reduce the movement in and around townships (Madikane, 2020).

Relating to additional and their future information needs, SMMEs will need to be nudged into seeking novel ideas or niche areas for them to survive (Madikane, 2020). In order to do this, they needed to get back to their jobs, start spending and generating revenues so that the economy can improve. One of the strategies considered by the municipality was to utilise their capital and operational budgets to facilitate job creation. Providing the necessary information for employers and their employees to come back to the townships and their communities and spend their income, was thus critical for entrepreneurs to start operating and spending again. Despite the lockdown, people came to the municipal offices, because they needed to 'get back on their feet' and start earning an income. Madikane (2020) further stated that in July 2020, the Overstrand Municipal Office had more than 300 walk-in enquiries, mainly people who came to look for jobs and those who came for enterprise support. A long list of SMMEs who came to offer their services was then made, following the walk-in enquiries from SMMEs who wanted to know how they could be brought into the supply chain processes of the municipality. Apart from involving SMMEs and information-sharing of municipal SCM processes, business-to-business relationships were also utilised to avail SMMEs with developmental opportunities. From a digital point of view, just prior to the lockdown, the municipalities engaged an organisation to teach business people as well as the broader community, how to utilise the available functions on their smartphones to the fullest extent. An e-learning centre was then set up during the lockdown period. This enabled the municipality to start an e-learning process, and used smallclass zoom meetings to conduct training. These sessions were also used to disseminate information about the effect of Covid-19 and the lockdown regulations. Thus, people were provided with necessary information as well as effectively empowered them with better use of tools available on their smartphones. The online zoom classes are one example of the municipality's intervention to migrate people onto digital platforms and advance a digital approach to empowerment (Madikane, 2020). 


\section{Interventions to increase access to finance and overcome financial challenges}

As a result of the Covid-19 lockdown, resources that small and microbusinesses would normally have had at their disposal, were depleted during the months immediately following the lockdown. As mentioned previously, municipalities also did not have the funds to assist small and microbusinesses, as the budgets had been approved prior to the outbreak of Covid-19 and the imposition of the lockdown. Due to the stringent rules that businesses have to comply with in terms of the municipal supply chain processes, it is also very difficult for small and microenterprises in particular to access the resources that are available. This is where institutions directly tasked with developing SMMEs, such as SEFA and SEDA have to provide support and assistance to struggling SMMEs (Madikane, 2020). However, as SEDA can only really assist informal businesses to get registered, the Western Province Department of Economic Development and Tourism (DEDAT) initiated a financial process to assess directly and quicker SMMEs that may require business rescue. This bypassed the need for small and microenterprises to first overcome the 'more stringent compliance matters' that SEDA focusses on. Municipalities will also have to effect red tape reduction strategies to ensure that the growth and development path of SMMEs is viable and not unnecessarily hamstrung. This is critical as no empirical information is available to show how small and microbusinesses, including those in the informal sector, will or can survive, and how people will continue to make a living during the economic lockdown and subsequent periods thereafter. Their need for financing is also increasing in importance. As municipalities cannot provide the necessary funding, because among others, constraints brought about by the PFMA ${ }^{2}$, more options such as microfinancing need to be looked at to stimulate and encourage the investment appetite of small and microenterprises. The opportunities of partnering with other municipalities within the districts and provinces, may also provide the platform for developing a more enabling environment for SMMEs (Madikane, 2020).

Within the constraints of the Overstrand Municipality's capital and operational budget, the decision was made to train as many people and involve as many emerging SMME subcontractors as possible, as part of the implementation process. The municipality is thus revisiting their supply chain management (SCM) processes and trying to encourage more SMMEs to participate. In effect this means 'involving everybody in a little piece of the process'. Construction services, a sector where municipalities procure millions of rands of goods and services, is a good example of where these opportunities lie. It is also a very highly competitive environment, as there are many suppliers and contractors in the sector. As municipalities change their approach to SCM, it requires that contractors understand the new approach adopted by the municipalities and understand in which area/s they can provide goods or services potentially. Consequently, municipalities are now tasked with setting up enterprise development programmes, allowing people to provide support services or do business with the municipalities. The aim is that by the end of the financial year, many businesses would have participated in this process (Madikane, 2020).

Another intervention which the Overstrand Municipality will focus on, is the development of the 'one house one household' community garden concept. This involves people starting to grow their own food and supply to the existing market. When people are able to participate in production opportunities such as these, and earn an income as opposed to receiving a handout from a soup kitchen, it can positively affect the dignity of people. It is also an initiative that can help people who have lost their jobs and who do not have much money to start more capitalintensive enterprises. Furthermore, it contributes goods and services to the market economy within the localities where people need access to the basic necessities such as nutritious food. In addition to this, municipalities will also adopt more sectoral-specific approaches to development. This will allow people to focus on particular opportunities and reorganize their businesses for the market needs in a specific sector. However, it is also important that SMMEs understand that they cannot stick to the same type of business or strategy if it is not viable. They need to assess their businesses over different time periods and continue to look for opportunities and find innovative solutions to expand their offerings, for example, fulfilling peoples' need for safety. Various opportunities exist around the need for safety. Apart from the need for personal protective equipment (PPE), different opportunities exist around the provision of PPE. Community safety, prevention and training are a few examples. What has been considered 'normal' prior to the Covid-19 pandemic, is very different and will be different in the various stages of and the period following the pandemic. Local municipalities will see many more people coming to request assistance in terms of their livelihoods, and who seek different means to augment their incomes. They will be looking for jobs or different kinds of enterprise support. Municipalities, therefore, have to adopt more inclusive supply chain processes, as well as implement enterprise development programmes as part of their operations (Madikane, 2020).

\footnotetext{
2 Public Finance Management Act, (PFMA), 1999 (Act No. 1 of 1999) (as amended by Act No. 29 of 1999)
} 


\section{Role of the Private and Third Sector}

"The need of many SMMEs for funding is a need larger than what any one organisation on its own can fulfil." (Savarian Arendse, Chair of the Provincial Management Board of Old Mutual, Western Cape)

Arendse (2020) stated: "the need of many SMMEs for funding is a need larger than what any one organisation on its own can fulfil." This holds true, even for Old Mutual, which is one of the largest insurance companies in South Africa, and a pan-African investment, savings, insurance, and banking group listed on the Johannesburg, Zimbabwe, Namibia and Botswana Stock Exchanges. During the Covid-19 pandemic the company has been inundated with requests for funding and related support (Arendse, 2020). This includes information on how to access finance, particularly through the Masisizane Fund, which was established by Old Mutual to offer financial and non-financial support to SMMEs in South Africa's most vulnerable communities ${ }^{3}$. Due to the great need which SMMEs have in order to survive and grow their businesses, Masisinane and Old Mutual's approach is to collaborate with partners who can assist with funding and non-financial support to SMMEs. Its funding partners include organisations across a broad spectrum of society, from academia to NGOs such as the South African Supplier Diversity Council (SASDC). Old Mutual reached out to their partners in academia, government, certain NGOs and civil society at large. One of their partner organisations in Johannesburg, who are also growing their presence in other provinces, assists them from a development perspective to help small businesses become more compliant. According to research conducted by Old Mutual, businesses couldn't access approximately $60 \%$ of all funding that was available. This was because they were not compliant, i.e. not meeting one or other criteria required to obtain necessary funding or support. Consequently, Old Mutual in partnership with SASDC, thus focussed on helping SMMEs become compliant faster, and to remove the red tape to do business and to do it in a more sustainable way. Through the development arm of South African Supplier Diversity Council, Old Mutual is able to 'certify' that a particular small business is compliant. This helps small businesses as other organisations are then more able to do business with compliant small businesses. Part of the requirement is that the businesses are transformational and have a development arm. This is part of Old Mutual's 'solving for the future and co-creation strategy' that they adopted to support SMMEs. Their other organisational partners include SEDA, provincial local government organisations such as the Department of Economic Development and Tourism (DEDAT), and local municipalities (Arendse, 2020).

One of the initiatives Old mutual instituted during the Covid-19 pandemic was to assist SMMEs with information on where they need social distance and to highlight the importance of complying to the five principles of how to stop the spread of the virus. As a practical response to the Covid-19 pandemic, they also launched a vigorous financial education campaign, called 'On-the-Money'. The purpose of the campaign is to assist business owners to assess their own personal finances and help them manage and navigate the challenges brought about by the Covid-19 lockdown and the pandemic in general. This is done using an accredited programme, which employs certified trainers to help SMMEs apply various budgeting principles to their personal finances. This helps to educate SMMEs and increase their understanding of why cash flow is important, as well as various ways to free up different cash flows. The objective is to help them to become financially more sustainable. In order to achieve this, Old Mutual adopts a listening approach and collaborates with SMMEs to help them navigate towards a better financial future. This is important because 'despite being part of a big company, big companies do not always have all the answers' (Arendse, 2020). Furthermore, the Covid-19 pandemic and the lockdown has also highlighted the increasing importance of digital skills. People and institutions will need to learn and develop ways to leverage digital skills and the necessary platforms to build on that.

"The digital era may be the great equalizer for the world. We don't always have all the answers, but its better solving together for the future" (Arendse, 2020).

\section{Role of Universities}

The role of universities towards mitigation and contribution towards solving the myriad problems faced by SMMEs and that which have been exacerbated by the Covid-19 pandemic, includes the provision of training and mentorship for small businesses. This can be facilitated by helping small and microbusinesses develop and integrate Information Technology (IT) and digital strategies into their sales, distribution and supply chain processes. Professor Shaun Pather, who heads the Information Systems Department in UWC's Faculty of Economic and Management Sciences, stated that this can help address some of the major problems SMMEs face during pandemics and periods of lockdown. However, some of the challenges they face appear to be attributable to larger structural problems in the

${ }^{3}$ Old Mutual. The Masisizane Fund-Supporting SMMEs 
broader ecosystem. These will need to be addressed at higher levels. Despite these, support is available to small businesses, if they are able to access it and find the right development partners. However, more assistance can be made available if the ecosystem challenges can be addressed - by looking at ways to make it more integrated and cohesive for small and micro-entrepreneurs. This can provide a good foundation to help develop and empower SMMEs to adopt and rely more on ICT services as an effective and integral tool in their development arsenal (Pather, 2020).

\section{Conclusion}

The lessons learnt from the lockdown stories and the experiences of small businesses, as told by the participants in this webinar series, have highlighted the fact that municipal supply chain processes do not adopt a value chain perspective. For example the government has not paid sufficient attention - they even neglected - the contribution of the actual, i.e. primary producers of core products, such as vegetables, that are provided to soup kitchens. As noted during this webinar series, large distributors and retailers are given government supplier contracts to supply community soup kitchens. What then are the opportunities that remain for small-scale primary producers who, forced by the bargaining power of large retail groups, have to supply their fresh produce at a very low cost (and often at a loss) to larger distributors and retailers?

The series has also highlighted a host of related major issues concerning the effects of Covid-19 on small and microenterprises that need particular attention. These include initiatives and incentive schemes that can be put in place to buffer small-scale producers from the realities of operating in oligopolistic markets ${ }^{4}$. Also, what interventions can be instituted to help level the playing fields between smaller and big businesses and to reduce the opportunity and income inequalities inherent in South Africa's supply markets? This is particularly important in areas concerning the production and consumption of food, which is a basic necessity. Other basic needs, such safety and security, also provide opportunities. For example, the need for basic infrastructure (adequate housing and schools that are not overcrowded) provides opportunities in the construction industry and a chance for municipalities to partner in more inclusive value chains in these sectors. The Covid-19 pandemic and lockdown has also exacerbated the need for digital infrastructure. This offers major opportunities for government, businesses and educational institutions to build the required platforms and required skills for the foundation of the fourth Industrial Revolution (4IR) and beyond. These are issues unearthed by the lockdown that require all levels of government, businesses, universities, research institutions, and the NPO sector to collaborate and seek solutions - particularly concerning the ability of small and microbusinesses to survive and create jobs, even amidst pandemics such as Covid-19 and in a postCovid-19 era.

In this webinar series, major challenges that small businesses face and that resulted from the pandemic have been highlighted. This provides government, particularly at provincial and local government levels, with opportunities to improve the effectiveness of their supply chain processes. As the starting point of a more integrative approach to tackling inequality and poverty in South Africa, a more responsible government and business sector for instance, can pay more attention to who the real producers of food in the real economy are, and ensure that the prices they are paid are fair and cover at the minimum their operational costs in order to survive. This requires that not only first-tier suppliers who generally manage entire supply chains be adequately compensated, but that all the suppliers of core products and services should be paid in a more fair and equitable trading environment. In the long run this may lead to a growing and more inclusive local supply chain and a more sustainable food supply system. Reduced food 'wastage' and artificial 'shortage' brought about by 'inflated' retail prices ${ }^{5}$ may also be a result.

Corporates can also revisit their supply chain and procurement practices and bring small business into their value chain in more inclusive and fair ways. This may unlock hidden potential that also benefits large corporates with the involvement of more agile small businesses. Small businesses may also benefit from access to funding facilities that bigger corporates can provide them with. In this way, more cooperative-type relationships between small and relatively big businesses may spawn inclusive-type growth increasingly, opening up the field of opportunities across the entire business community, its major stakeholders and across society in general. Rather than the traditional competitive orientation evidenced by big business in South Africa, a shift in mindset, i.e. by viewing small businesses as suppliers of value to big business, South Africa Inc. may start to bridge the divide between small and big businesses in South Africa.

\footnotetext{
${ }^{4}$ an oligopolistic market (an oligopoly) is where a few companies rule over many in a particular market or industry, offering similar goods and services. (Corporate Finance Institute.com)

${ }^{5}$ Grocery prices in South Africa spiked during lockdown - but still haven't returned to normal, 2020. Commission to deal with suppliers who inflate prices, 2020.
} 
Big businesses therefore have a large role to play in developing sustainable, local supply chains. This requires SMME development through more inclusive participation in their value chains. This may prove challenging for larger businesses who operate under increasing pressure from global competitors. However, many of what might be challenges for large businesses, who are often hampered by their layered governance and or silo-based organisation structures that impede their flexibility, can be opportunities for SMMEs. Due to simpler organisation structures, fewer employees and reduced legacy systems and processes to overcome, small businesses tend to be more agile, and respond faster to opportunities and turbulence in the business environment. These are characteristics that small and microbusinesses may leverage. On the other hand, despite their superior agility, small businesses are also more fragile, as they often have less cash reserves than their larger counterparts. Thus, during economic downturns and lockdowns as evidenced by the Covid-19 pandemic, small businesses tend to be affected the most. However, Business South Africa can be winners when big and smaller businesses - particularly larger corporates - adopt more inclusive, cooperative relations with their suppliers and increase the distribution of value. Opportunities abound in key sectors such as in the financial, production and retail sectors, where a more shared-value approach ${ }^{6}$ can help grow more sustainable markets and operations. More sustainable and equitable business operations are proving to be more critical during protracted economic downturns and crisis. The vision of achieving more sustainable - both economic and social business ventures and strategic partnerships between small and larger suppliers of all forms of capital, financial and non-financial - has to include the critical elements of developing human capital, up- and reskilling South Africa's burgeoning unemployed youth into a new generation of entrepreneurs operating micro-, small-, and medium-sized businesses, the incubators of big businesses.

Following this webinar series, some of the key aspects to consider for stakeholders involved in small business development, are the different types and support measures available to small and microbusinesses, including the informal and survivalist-type businesses; fair competition and providing more equitable opportunities, i.e. helping to level the playing fields between micro, small, and larger enterprises. These can be through more targeted and effective skills development and supplier development programmes, business incubators and or accelerators. Thirdly, technology may be used to augment and even catalyse the development of small businesses, particularly youth and female-run businesses. This is important, as Covid-19 has exposed, and in some cases may even have widened the gender divide in certain contexts and countries. A lack of access to technology by women has been a contributing factor. The field of opportunity to spur on small business growth and development by various stakeholders - development agencies, researchers and business practitioners - looms large. Instead of focusing on the challenges, organisations in and across the various value chains can build diversity into it; focus their efforts on building solutions to construct more efficient, effective development pathways out of the myriad, complex business and societal challenges affecting producers, distributors and consumers alike. In the process, new knowledge is created which entrepreneurs can act upon. Amidst the challenges, new opportunities exist and can be uncovered if people across the spectrum of society are encouraged to adopt an entrepreneurial perspective and mindset.

\section{References}

Corporate Finance Institute. Knowledge Resources. Available at: https://corporatefinanceinstitute.com/resources/ knowledge/economics/oligolistic-market-oligopoly/ [Accessed November 17,2020].

Grocery prices in South Africa spiked during lockdown - but still haven't returned to normal, (2020). Businesstech, December 15. Available online at: https://businesstech.co.za/news/finance/457256/grocery-prices-in-south-africaspiked-during-lockdown-but-still-havent-returned-to-normal/ [Accessed January 12, 2021].

Lockdown forced nearly half of small businesses in South Africa to close: study, (2020), Businesstech, December 7. Available online at: https://businesstech.co.za/news/business/455100/lockdown-forced-nearly-half-of-smallbusinesses-in-south-africa-to-close-study/ [Accessed: 15/01/2021].

Moodley, P, (2020). Foreword. Nine Yards. Available at: https://issuu.com/nineyards/docs/_nine_yards_ issue_1_2020_issuu [Accessed: 30/11/2020].

Network Readiness Index Report (2019). Available online at: https://networkreadinessindex.org/

Old Mutual Masisizane Fund. Available at: https://www.oldmutual.co.za/business/solutions/masisizane. [Accessed November 20, 2020].Small Enterprise Development Agency (SEDA). Available at: http://www.seda.org.za/Pages/ Financing.aspx [Accessed: 18/11/2020].

${ }_{6}^{6}$ Moodley, P. (2020:3). Nine Yards, Issue 1 
Small Enterprise Finance Agency. https://www.sefa.org.za/about/history [Accessed November 18, 2020].

South African National Treasury., (2003), "Public Finance Management Act No. 1 of 1999", South Africa.

National Planning Commission (2012) National development plan 2030. Retrieved October 30, 2020 from https:// www.poa.gov.za/news/Documents/NPC\%20National\%20Development\%20Plan\%20Vision\%202030\%20-lo-res.pdf.

South African Government (2020), Commission to deal with suppliers who inflate prices. Available from: https:// www. sanews.gov.za/south-africa/ [Accessed October 14, 2020]. South African Department of Telecommunications and Postal Services, 2016. White Paper on National Integrated ICT Policy. September 2016. Available at https:// www.dtps.gov.za/images/phocagallery/Popular_Topic_Pictures/National_Integrated_ICT_Policy_White.pdf [Accessed October 28, 2020].

The Masisizane Fund: Supporting SMMEs. Available at https://www.oldmutual.co.za/corporate/resource-hub/allarticles/the-masisizane-fund-supporting-smmes/ [Accessed November 19, 2020]. 